\title{
International Organizations:
} A Comparative Approach to the Management of Cooperation

\section{Libros}

Jordan, Robert S., Clive Archer, Gregory P. Granger y Kerry Ordes, Londres 2001, $4^{\mathrm{a}}$ ed., 304 páginas.

La fotografía de Eleanor Roosevelt con la Declaración Universal de Derechos Humanos en sus manos, tomada en noviembre de 1949 en la sede transitoria de las Naciones Unidas en Lake Succes, New York, es la primera figura de entre múltiples esquemas, cuadros demostrativos y gráficos que contiene el libro, y constituye un hito histórico y referente que determina la forma en que desarrolla el autor el tema del manejo, gestión y administración de la cooperación de los organismo internacional. En efecto, divide su exposición entre «El pasado y el presente», compuesto por cinco capítulos, el primero de los cuales es una descripción analítica, a modo de introducción, de tales entidades y, «El presente y el futuro», que comienza con la influencia de los conflictos armados en las organizaciones internacionales y concluye preguntándose ¿está listo el mundo para la sociedad civil?

Parte su análisis constatando un cambio entre los inicios de la historia moderna y fines del siglo XX respecto de la primacía del Estado como principal actor de la política internacional, dando cabida a organizaciones no gubernamentales (ONG), y organizaciones internacionales gubernamentales (OIG), como consecuencia del fenómeno de la globalización y las particularidades 
subnacionales. Cataloga la proliferación de tales organizaciones internacionales como la manifestación del idealismo wilsoniano de un incipiente gobierno global a través de algunas formas de representación basadas en el consentimiento popular, pero cuyo proceso permanece incompleto y con resultados confusos. El surgimiento de estas entidades fue consecuencia de la búsqueda, por parte de los Estados modernos, de materias primas y mercados dentro del naciente mercantilismo mundial después de la Guerra de los 30 años. Singular explicación da al término «Institución», identificándola como una entidad que refleja o puede reflejar la experiencia colectiva humana en toda su amplitud. Con ello grafica, románticamente y de gran forma, la extensa gama de potencialidades, virtudes y vilezas que pueden llegar a albergar.

Para aproximarse al estudio de las organizaciones internacionales propone varios tipos de acercamiento: uno histórico, que contempla la determinación de los hechos de la humanidad en su gestación y desarrollo; una arista legal, que las explica dentro de su ordenamiento jurídico; una perspectiva estructural funcional, que responde a la pregunta qué deben hacer y cómo lo van a hacer. Finalmente, propone como punto de vista el análisis de la toma de decisiones, manejando conceptos de «gobierno global», «régimen»y «sociedad civil».

Dentro del creciente pluralismo de la comunidad internacional, de naturaleza descentralizada y reticente a la sistematización u orden, propone el desafío de medir o evaluar el rol primario de las organizaciones internacionales: el manejo o administración de la cooperación bajo condiciones de creciente independencia.

En el capítulo segundo efectúa diversas clasificaciones de las organizaciones internacionales -constatando la mayor complejidad de tal ejercicio respecto de las ONG- y destacan la efectuada por la ciencia política, según sus características organizacionales, funcionales y políticas; su ámbito de competencia, y la forma en que gestiona la cooperación. Para tales efectos, respecto de las OIG se debe atender: a) al grado de satisfacción de las necesidades; b) a la calidad del desarrollo de su política, de la puesta en práctica, y de los resultados; c) a la calidad de liderazgo ejecutivo; d) a la administración y a las habilidades para resolver problemas por los ejecutivos; y e) a la naturaleza y capacidades de sus funcionarios. 
En el capítulo tercero se pregunta ¿qué motiva a los Estados a Libros crear OIG? Afirma que la respuesta a esta pregunta proporciona significativas pistas respecto de su durabilidad y de los cambios previstos del rol de estas instituciones. Recuerda al lector que ha sido la búsqueda de intereses particulares de los gobiernos lo que dio lugar al establecimiento de OIG, y en ese contexto insiste en cuestionarse bajo qué condiciones específicas un gobierno recurre a una OIG para satisfacer sus intereses. Parte de la base de que, normalmente, un gobierno utilizará primero medios nacionales para resolver sus necesidades económicas, científicas, tecnológicas de seguridad y desarrollo, por cuanto si decide a llegar a impulsar la creación de una OIG o asociarse a una ya existente, su autonomía o libertad de acción quedará inevitablemente, circunscrita en cierto grado. Además, las relaciones con otros Estados miembros de la OIG imponen restricciones a las acciones y comportamientos de todos los gobiernos que participan en ella. En caso de dudas, pone como ejemplo la participación de los Estados miembros de la OTAN en actividades multilaterales de pacificación o mantenimiento de la paz, tales como las realizadas en África occidental, en Somalía y Camboya, Irak y Serbia.

Aborda la influencia de los Estados en las organizaciones internacionales y considera como fracaso su utilización por parte de sus miembros para perseguir o satisfacer sus intereses particulares. Utiliza como caso ilustrativo el régimen de control de las armas convencionales, químicas, nucleares y de destrucción masiva, analizándolo desde una perspectiva mundial y regional. Posteriormente, se adentra en los costos y beneficios para los Estados de los alcances y estructuras de las organizaciones internacionales, centrándose en el desarrollo de la OTAN, particularmente, en sus adaptaciones político-institucionales.

En el capítulo cuarto propone analizar las organizaciones internacionales, sean o no gubernamentales, desde la perspectiva de la ideología organizacional que subyace sus tareas u objetivos, la cual puede determinar su funcionamiento, y cómo puede fortalecerla su eficiencia directiva y la efectividad de su liderazgo.

Afirma que la estructura de las instituciones se identifica como otro factor que afecta el funcionamiento de su tarea, al igual que la innovación en los procesos. Critica el aumento de la burocracia al interior de los organismos internacionales y cómo tal hecho puede 
llevar a crear nuevas tareas o nuevos órganos, distorsionando su motivación primitiva o haciéndola ineficiente. La naturaleza y la forma de este marco institucional deben relacionarse obviamente con la función y las tareas específicas que se espera que la OIG realice. Factores políticos, sin embargo, se imponen a las consideraciones puramente racionales de un modelo eficaz de gerencia. Esto tiene un impacto no solamente en los detalles de su organización, sino también en el poder conferido por los Estados miembros $y$, por lo tanto, en la administración de la cooperación.

Pone atención en los procesos administrativos que permiten que las OIG realicen sus tareas, constatando la gran variedad de estas entidades y el grado de sus operaciones: políticas, arbitrales, de mantenimiento de la paz y actividades del servicio (tales como la efectuada por la Organización Mundial de la Salud, con un programa para el sida). La razón por la cual emprenden estas tareas es porque pueden hacerlas mejor que el Estado nacional, o bien porque por su naturaleza constituyen actividades que no respetan fronteras $y$, por lo tanto, requieren de una respuesta internacional o multinacional. En detalle, la OIG debe tener una ideología de organización fuerte: un sentido de donde va y de cuál es su meta. Tal ideología se puede consolidar también gracias a otros elementos: la eficacia y la dirección de la gerencia. Este ha sido el caso de la OTAN, que ha tenido una administración relativamente fuerte y una dirección decisiva que le han permitido proporcionar ayuda institucional e intervenciones de carácter humanitario. Las estructuras de organización son también importantes para la administración internacional. Si estas son poco manejables o débiles pueden conducir su inadecuado funcionamiento, y los miembros decidirán emprender las tareas ellos mismos o elegir otra organización para cumplirlas. Por otra parte, la innovación en los procesos proporciona otro elemento que puede determinar su funcionamiento. Quizás el elemento más importante para determinar el éxito de las OIG en el cumplimiento de sus funciones es la actitud de los miembros. Por ejemplo, el fuerte interés de los Estados Unidos en la OTAN ha sido el factor decisivo de su sostenido éxito.

En el capítulo quinto, postula a las organizaciones internacionales universales como una necesidad práctica. Indica que la predisposición básica para crear las Naciones Unidas, así como su 
precursora, la Liga de las Naciones, era evitar la pérdida devastadora de vidas y de características causadas por dos guerras mundiales catastróficas. La meta era que si se lograba resolver los conflictos internacionales en forma pacífica, se lograría la seguridad de todos los Estados. No obstante, el hecho de que Estados Unidos no perteneciera a la Liga contribuyó a su ineficacia para mantener la paz durante los años treinta y fue un estímulo para que ese país fuera miembro de las Naciones Unidas. Los intentos realizados en los años cuarenta por el Reino Unido y Estados Unidos y China y la URSS no fueron sino la expresión de la necesidad de contar con un organismo internacional de carácter mundial. En tal contexto, analiza el surgimiento de las Naciones Unidas, la creación del Banco Mundial y de otros bancos de desarrollo regionales para la reestructuración económica en la post guerra, y la participación de otras organizaciones internacionales de carácter mundial.

En el capítulo sexto aborda las entidades transnacionales, subnacionales y «transfronterizas» a propósito de la problemática étnica de kurdos, albaneses, tutsis y hutus, que por su naturaleza ha trascendido las fronteras de los Estados nacionales, particularmente en materia de migraciones y refugiados. Las respuestas cada vez más transnacionales a estas complejidades, las dificultades de las intervenciones humanitarias internacionales, particularmente su coordinación, y el fenómeno del blanqueo internacional de dinero, son el centro del análisis.

Afirma en su capítulo séptimo que en el período posterior a la Guerra Fría no existe una demarcación clara entre las acciones civiles y militares de pacificación, mantenimiento o reforzamiento de la paz. En conflictos contemporáneos la violencia se emprende a menudo dentro de las fronteras de los Estados. Las actividades genocidas en Ruanda, el pillaje de aldeas en Argelia, el uso de la violación como instrumento de guerra en los Balcanes, la lucha de los cárteles de la droga en Colombia, y la utilización creciente de la tortura por parte de los gobiernos, ejemplifican los retos que enfrentan los esfuerzos de codificación y por hacer cumplir reglas de conducta en la guerra.

Se adentra en el desorden civil y en las acciones multilaterales de pacificación, mantenimiento e imposición de la paz analizando con especial interés el rol del Consejo de Seguridad de las Nacio- 
nes Unidas, la penalización de ciertos actos de guerra, y la necesidad de la Corte Penal Internacional. Además, aborda nuevas formas de cooperación entre organismos internacionales no gubernamentales y gubernamentales y el surgimiento de organismos internacionales privados que desarrollan actividades de seguridad y de combate.

$\mathrm{Si}$ bien es prematuro decir que la guerra tradicional entre los estados, para luchar por territorio, recursos naturales, por la limitación de las armas o por relevancia internacional, es cosa del pasado, expresa que es necesario reconocer que la naturaleza de los conflictos ha cambiado: la guerra armada se presenta en el contexto de emergencias humanitarias complejas, a menudo actuando como causa y consecuencia de un ciclo económico, o bien, con motivo de una crisis de refugiados. Las fuerzas de pacificación indican el grado de vulnerabilidad del sistema westfaliano (soberanía de los Estados en sus asuntos internos y supremacía del principio de no intervención). La tendencia tanto de los gobiernos como de las OIG y de las ONG es intervenir en tragedias internas, por lo que las funciones humanitarias, políticas, y militares se han transformado en un elemento establecido y significativo del sistema internacional. Por otra parte, el esfuerzo de institucionalizar normas de justicia para el procesamiento criminal internacional de individuos es un potente catalizador potencial para un cambio adicional.

Indica que las transacciones transnacionales legales, extralegales, e ilegales y que las líneas que separan estos tres tipos tampoco son evidentes. Por tal razón, destina este capítulo a examinar este dilema, constatando que las definiciones convencionales de OIG o de ONG no contemplan todas las interacciones de las organizaciones internacionales: nada ilustra mejor este punto que el tráfico internacional de droga y el blanqueo internacional de dinero.

Examina la relación entre las tendencias regionalistas y la globalización en materia de acuerdos y en el rol de las entidades subnacionales, públicas y privadas, dentro de dicha relación, en materia de inversión, desarrollo y asuntos monetarios.

Concluye que para analizar el actual contexto internacional, hay que considerar, además de las categorías tradicionales de participantes (estados, OIG, ONG), otros actores (legal, extralegal, e ilegal), y mayores delimitaciones geográficas (regionales y subregionales). 
Antes de ocuparse del concepto de gobierno global aborda el tema de la toma de decisiones en el ámbito internacional, sus fuentes formales e informales, complementada con la realidad, aún constante, de que los Estados miembros todavía controlan la agenda internacional y señala que durante la post Guerra Fría, ese proceso se ha tornado cada vez más complejo, caracterizándose por influencias interinstitucionales. Para fines pedagógicos, recoge la clasificación de las decisiones de Robert Cox y Harold Jacobson, que distinguen entre pragmáticas, esto es, de carácter estratégico; de regulación o sustantivas; operacionales, de supervisión, de delimitación de su acción y simbólicas, que constituyen declaraciones ideológicas.

Finalmente, en los dos últimos capítulos, expresa que los extraordinarios adelantos en comunicaciones y tecnologías de la información están creando oportunidades para una amplia gama de actividades fronterizas o transnacionales. En el lado positivo, estas actividades permiten que la gente participe junto con gobiernos en virtualmente todos los aspectos del gobierno global, aunque su preponderancia está lejos de ser igual. En el lado negativo, las organizaciones criminales transnacionales, las células terroristas independientes, las transferencias electrónicas ilegales de fondos, entre otros, también se benefician de las comunicaciones y de las redes de informaciones fluidas e instantáneas. En suma, las organizaciones internacionales deben adaptar sus estructuras, misiones, y correlaciones para manejar la cooperación de modo de crear cierto orden y previsibilidad en el sistema.

\section{LA SOCIEDAD CIVIL}

Por el momento, el propio concepto sigue siendo nebuloso. Una sociedad civil global sería una que abarcara toda la humanidad, reduciendo al mínimo los criterios nacionales. Si bien, resulta evidente que persisten enormes obstáculos que impiden tal evolución de la organización humana, en cierta medida existe una sociedad civil global (o planetaria) incipiente. Si bien la literatura empuja en esa dirección, respecto de la naturaleza y el grado de evolución de la sociedad civil, nos limitaríamos al idealismo pragmático. Es decir, aceptamos aquello con que tenemos que trabajar en términos de la naturaleza del sistema internacional contemporáneo, mientras que 
buscamos maneras de hacer mejor las cosas manejando la creciente diversidad. Ambos son aspectos del gobierno global. La diversidad de gente, culturas, han hecho que sociedades del mundo se resistan al cambio acelerado como para poder proclamar el inicio de una sociedad civil universal armoniosa. Por otra parte, si los esfuerzos por crear una sociedad civil a escala global, no se preocupan por administrar adecuadamente la cooperación, se crean trampas potenciales. Los organismos internacionales son un componente fundamental del concepto de sociedad civil global, pero mientras más se adentren en áreas comerciales y dependan de ayuda, más requerirán de los gobiernos. Mientras crezcan más cercanas a las élites del mundo en el gobierno, el negocio y finanzas $ఓ$ efectivamente se convierten en agentes más eficaces del cambio?

\section{CONCLUSIÓN}

El texto, sin duda, es un gran aporte para aproximarse al derecho internacional, particularmente por la forma de exponer conceptos junto con ejemplos prácticos que facilitan una mejor comprensión de algunos temas, de suyo complejos. Destacable es el pragmatismo con que los autores exponen sus ideas y en algunos pasajes expresan, bastante crudamente, el real calibre de las organizaciones internacionales y la resignación de los Estados para tolerar su existencia y/o su interés en manejar a través de su permanencia, sus propios intereses. Quizás su mayor logro es destronar, al menos desde la cátedra, al Estado como jugador preponderante en el contexto internacional y adentrarse en el campo de las organizaciones internacionales, abandonando el idealismo o las utopías. Sin embargo, una crítica negativa, que podría ser injusta, es que su contenido está dirigido a estudiantes, pero no a estudiosos del derecho internacional y que, en algunas oportunidades, los casos prácticos revisten mayor importancia que las ideas que pretenden ilustrar.

Mauricio Andrade Vergara Programa de Magister en Derecho Internacional, Inversiones y Comercio (L.L.M.) Universidad de Chile - Universidad de Heidelberg, 2005 